Article

\title{
Effect of Mixed Commercial Cold Flow Improvers on Flow Properties of Biodiesel from Waste Cooking Oil
}

\author{
Siyu Nie and Leichang Cao * \\ Miami College, Henan University, Kaifeng 475004, China; niesiyu@vip.henu.edu.cn \\ * Correspondence: clch666@henu.edu.cn; Tel.: +86-1391-716-4174
}

Received: 8 August 2020; Accepted: 29 August 2020; Published: 3 September 2020

check for updates

\begin{abstract}
The uniform design method was used to screen the solidifying point depressing effects of 18 traditional diesel cold flow improvers on biodiesel derived from waste cooking oil. The cold flow improvers with good effects were selected for orthogonal optimization. Finally, the mixed cold flow improver (CFI) with the best depressing effect was selected to explore its depressing mechanism for biodiesel. The results show that the typical CFIs such as A132, A146, 10-320, 10-330, A-4, CS-1, AH-BSFH, Haote, T1804D, and HL21 all have a certain solidifying point depressing effect on biodiesel, while other cold flow improvers had no obvious effect. Amongst them, 10-330 (PMA polymer) and AH-BSFH (EVA polymer) had better solidifying point depressing effects over others, both of which reduced the solidifying point (SP) of biodiesel by $4{ }^{\circ} \mathrm{C}$ and the cold filter plugging point (CFPP) by $2{ }^{\circ} \mathrm{C}$ and $3{ }^{\circ} \mathrm{C}$, respectively. From the orthogonal mixing experiment, it can be seen that the combination of 10-330 and AH-BSFH at a mass ratio of 1:8 had the best depressing effect, reducing the solidifying point and cold filter plugging point of biodiesel by $5^{\circ} \mathrm{C}$ and $3{ }^{\circ} \mathrm{C}$, respectively. Orthogonal analysis showed that when used in combination, AH-BSFH had a greater impact on the solidifying point, while the ratio of the combination had a greater impact on the cold filter plugging point.
\end{abstract}

Keywords: mixed cold flow improver; biodiesel; mechanism; orthogonal experiment

\section{Introduction}

Biodiesel refers to fatty acid methyl esters or ethyl esters derived from raw material oils such as crop oil, wild crop oil, engineered microalgae oil, animal fat, and waste cooking oil through transesterification with alcohols such as methanol or ethanol [1-3]. Biodiesel is a high-quality diesel substitute $[4,5]$ and is a typical "green energy" in term of its better carbon balance over fossil fuels $[6,7]$ and limited environmental impacts, e.g., higher $\mathrm{SO}_{2}$ emission in biomass planting and biodiesel production processes [8,9]. Vigorously developing of biodiesel has great strategic significance for solving the shortage of petroleum resources, reducing environmental pollution and the greenhouse effect, and ensuring national energy safety [10]. As an alternative fuel for petrochemical diesel, biodiesel has attracted wide attention from all over the world, and large-scale production has been formed in European and American countries [11]. The economic feasibility analysis of biodiesel [12,13], the selection of raw materials, the optimization of production process, and the research of biodiesel combustion emissions have been reported at home and abroad [14-17]. However, the solidifying point of biodiesel is generally around $0{ }^{\circ} \mathrm{C}[11,18]$. At low temperatures, the crystallization of fatty acid methyl esters in biodiesel often blocks the oil pipeline and filters, hindering the normal operation of the engine [19]. Therefore, improving the low temperature fluidity of biodiesel is a problem that must be faced and solved in the process of biodiesel research and development [20-22].

The measures that can be taken to solve the problem of poor low-temperature fluidity of biodiesel are: (1) Winterization $[23,24]$. This method has some problems, such as low yield and serious waste of resources; (2) Change the structure of biodiesel [25]. However, its cost is high which makes it difficult 
to achieve industrialization; (3) Mixing a certain amount of refined diesel [26]. Adding 2\% to 20\% volume fraction of biodiesel to petrochemical diesel can reduce the solidifying point by 7 to $10{ }^{\circ} \mathrm{C}$ [27]. Since the method to improve the low-temperature flow properties of biodiesel requires the addition of refined diesel, and the production of refined diesel in China is small and in short supply, making this method not feasible; (4) The addition of cold flow improvers (CFIs) [28,29], due to the small amount of addition and the low cost and easy to operate, it has become the first choice to solve the low temperature flow performance of biodiesel. There are few studies on solidifying point depressing of biodiesel at home and abroad, and a complete theoretical system has not yet been formed. There are few studies on the effect of commonly used CFIs on biodiesel, especially the research on the effect of CFIs on biodiesel solidifying point depressing mechanism is still lacking in China [30-32]. This study mainly investigated the CFI mechanism of the mixed CFI on biodiesel and investigated the CFI effect on a variety of commonly used CFIs on biodiesel. It has laid a certain theoretical basis to further study the interaction between CFIs and biodiesel and develop a new and efficient biodiesel CFI.

\section{Experimental}

\subsection{Reagents and Instruments}

SYP1022-2 multi-functional low temperature tester, Shanghai Boli Instrument Co. Ltd., Shanghai, China; DSC27HP Differential scanning calorimeter (DSC), Mettler Instrument Co. Ltd., Zurich, Swiss; X'Pert PRD X-ray diffraction (XRD), Malvern Panalytical Ltd., Malvern, United Kingdom; Polarizing optical microscope, Linkam Scientific Instruments Ltd., Redhill, United Kingdom.

\subsection{Experimental Part}

\subsubsection{Experimental Materials and Instruments}

The raw materials used in the experiment include: biodiesel, prepared from waste cooking oil according to our reported work [5,7]; Commercial diesel CFIs: P388, A132, A134, A146, A148, T803, V-300, IX-248, LZ-7749, V-385, 10-320, 10-330, A-4, CS-1, AH-BSFH, Haote, T1804D, and HL21.

\subsubsection{Determination of the Solidifying Point and Cold Filter Plugging Point of Biodiesel}

The solidifying point (SP) is the highest temperature at which the sample begins to lose fluidity under the specified experimental conditions. When the sample was placed in a prescribed test tube and cooled to an overdue temperature, the test tube was tilted 45 degrees for one minute and observed whether the liquid level moves.

The cold filter plugging point (CFPP) refers to the maximum temperature at which the test oil passes through the filter ( $363 \mathrm{mesh} / \mathrm{in}$ ) when the test oil passes through the filter is less than $20 \mathrm{~mL}$ in $1 \mathrm{~min}$ under specified conditions and under vacuum pressure of $1960 \mathrm{~Pa}[33,34]$.

\subsubsection{Differential Scanning Calorimetry Analysis}

The DSC curves of biodiesel samples before and after adding CFI were tested. The liquid sample was sealed in a miniature aluminum crucible, weighed and put into the instrument, in a high-purity atmosphere of $\mathrm{N}_{2}$, at a rate of $2{ }^{\circ} \mathrm{C} / \mathrm{min}$, from $5{ }^{\circ} \mathrm{C}$ to $-10{ }^{\circ} \mathrm{C}$ to record its DSC curve.

\subsubsection{Low Temperature Polarization Microscope Analysis}

Polarized light microscopy is a microscope used to identify the optical properties of the fine structure of a substance. Any substance with birefringence can be clearly distinguished under a polarizing microscope. Of course, these substances can also be observed by dyeing method, but some are not possible, and a polarizing microscope must be used. The low-temperature polarizing microscope adds a cooling function, which can easily observe the fine structure of the sample at a certain temperature. In this study, a low-temperature polarized microscope was used to observe the 
changes in the crystal form of the system crystals during the cooling process of the samples, and then to analyze the changes in the crystallization process caused by the addition of CFIs.

\section{Results and Discussion}

\subsection{The Effect of Various CFIs on Biodiesel}

The 18 commercially available CFIs were numbered according to their respective categories $(\mathrm{PAO}=$ poly-alpha-olefin; PMA = polymethyl acrylate; EVA (and PPD) = ethylene vinyl acetate copolymer; HPMA = polymaleic anhydride), to facilitate the design of experiments in groups during orthogonal experiments. The same amount $(0.1 \mathrm{wt} \%)$ of CFI was added to biodiesel to investigate their SP and CFPP reduction effects on biodiesel. The results are shown in Table 1.

Table 1. Effects of various CFIs on biodiesel.

\begin{tabular}{cccccc}
\hline Name of CFI & Numbering & $\mathbf{S P}\left({ }^{\circ} \mathbf{C}\right)$ & $\Delta \mathbf{S P}\left({ }^{\circ} \mathbf{C}\right)$ & $\mathbf{C F P P}\left({ }^{\circ} \mathbf{C}\right)$ & $\Delta \mathbf{C F P P}\left({ }^{\circ} \mathbf{C}\right)$ \\
\hline No dosage & - & 0 & - & 2 & - \\
\hline P388 & PAO-1 & 0 & 0 & 2 & 0 \\
A132 & PAO-2 & -1 & 1 & 1 & 1 \\
A134 & PAO-3 & -2 & 2 & 2 & 0 \\
A146 & PAO-4 & -3 & 3 & 0 & 2 \\
A148 & PAO-5 & -1 & 1 & 1 & 1 \\
T803 & PAO-6 & -1 & 1 & 2 & 0 \\
V-300 & PPD-1 & 0 & 0 & 1 & 1 \\
IX-248 & PPD-2 & 0 & 0 & 3 & 0 \\
LZ-7749 & PPD-3 & -2 & 2 & 2 & 0 \\
CS-1 & PPD-4 & -1 & 1 & 2 & 0 \\
Haut & PPD-5 & -2 & 2 & 0 & 3 \\
AH-BSFH & PPD-6 & -4 & 4 & -1 & 1 \\
HL21 & PPD-7 & 0 & 0 & 1 & 2 \\
10-320 & PMA-1 & -3 & 3 & 0 & 2 \\
10-330 & PMA-2 & -4 & 4 & 0 & 1 \\
A-4 & PMA-2 & -4 & 4 & 1 & 2 \\
T1804D & EVA & -3 & 3 & 0 & 0 \\
V-385 & HPMA & 0 & 0 & 2 & \\
\hline
\end{tabular}

It can be seen in Table 1 that A132, A146, 10-320, 10-330, A-4, CS-1, AH-BSFH, Haote, T1804D, and HL21 have a certain solidifying point depressing effect on biodiesel. Among them, 10-330 and AH-BSFH had a better solidifying point depressing effect, while other types of CFIs were not obvious. This showed that most of the commonly used CFIs had a certain CFI effect on biodiesel, but most of the CFIs were not particularly significant. Therefore, it is necessary to develop new and efficient biodiesel CFI or well-designed mixed CFI.

\subsection{Orthogonal Test and Analysis}

Based on single factor investigation, A132, A146, 10-320, 10-330, A-4, CS-1, AH-BSFH, Haute, T1804D, and HL21 were selected to design the mixed CFIs for the orthogonal test to determine the optimal mixed one and their weight proportions. The ten CFIs were divided into two groups according to their categories. Take PMA series (A), EVA series (B), and mixed ratio (C) as the three factors to carry out a three-factor five-level orthogonal experiment. The factor-level, orthogonal experiments (and results), and range analysis are shown in Tables $2-4$, respectively.

As shown in Table 4, to calculate the orthogonal experimental data, K1, K2, K3, K4, and $\mathrm{K} 5$ are used to represent the sum of the corresponding experimental results of each factor and each level. R1, $\mathrm{R} 2, \mathrm{R} 3, \mathrm{R} 4$, and $\mathrm{R} 5$ are used to represent the average value of each level to compare the quality of the different levels of each factor. The range $\mathrm{R}$ is to describe the influence of each factor on the experimental 
indicators, which is referred to the difference between the maximum value and the minimum value of R1, R2, R3, R4, and R5 in each column. The size of the range reflects the size of the effects of various factors in the experiment. A large range indicates that this factor has a large impact on the index, which is usually an important factor; a small range indicates that this factor has a small impact on the index.

Table 2. Factors-Level list.

\begin{tabular}{cccccc}
\hline Level & $\mathbf{1}$ & $\mathbf{2}$ & $\mathbf{3}$ & $\mathbf{4}$ & $\mathbf{5}$ \\
\hline PMA series (A) & PMA-1 & PMA-2 & PMA-3 & PAO-2 & PAO-4 \\
EVA series (B) & EVA & PPD-4 & PPD-5 & PPD-6 & PPD-7 \\
Mixed ratio (C) & $8: 1$ & $4: 1$ & $1: 1$ & $1: 4$ & $1: 8$ \\
\hline
\end{tabular}

Table 3. Orthogonal experiment design and results.

\begin{tabular}{|c|c|c|c|c|c|}
\hline Experiment Number & PMA Series (A) & EVA Series (B) & Mixed Ratio (C) & $\Delta \mathrm{SP}\left({ }^{\circ} \mathrm{C}\right)$ & $\triangle \mathrm{CFPP}\left({ }^{\circ} \mathrm{C}\right)$ \\
\hline 1 & PMA-1 & EVA & $8: 1$ & 0 & 1 \\
\hline 2 & PMA-1 & PPD-4 & $4: 1$ & 0 & 0 \\
\hline 3 & PMA-1 & PPD-5 & $1: 1$ & 1 & 0 \\
\hline 4 & PMA-1 & PPD-6 & $1: 4$ & 2 & 3 \\
\hline 5 & PMA-1 & PPD-7 & $1: 8$ & 3 & 1 \\
\hline 6 & PMA-2 & EVA & $4: 1$ & 2 & 1 \\
\hline 7 & PMA-2 & PPD-4 & $1: 1$ & 4 & 2 \\
\hline 8 & PMA-2 & PPD-5 & $1: 4$ & 0 & 1 \\
\hline 9 & PMA-2 & PPD-6 & $1: 8$ & 5 & 3 \\
\hline 10 & PMA-2 & PPD-7 & $8: 1$ & 3 & 1 \\
\hline 11 & PMA-3 & EVA & $1: 1$ & 1 & 0 \\
\hline 12 & PMA-3 & PPD-4 & $1: 4$ & 0 & 0 \\
\hline 13 & PMA-3 & PPD-5 & $1: 8$ & 1 & 2 \\
\hline 14 & PMA-3 & PPD-6 & $8: 1$ & 3 & 1 \\
\hline 15 & PMA-3 & PPD-7 & $4: 1$ & 3 & 0 \\
\hline 16 & PA-2 & EVA & $1: 4$ & 1 & 2 \\
\hline 17 & PA-2 & PPD-4 & $1: 8$ & 0 & 2 \\
\hline 18 & PA-2 & PPD-5 & $8: 1$ & 2 & 1 \\
\hline 19 & PA-2 & PPD-6 & $4: 1$ & 4 & 1 \\
\hline 20 & PA-2 & PPD-7 & $1: 1$ & 1 & 1 \\
\hline 21 & PA-4 & EVA & $1: 8$ & 3 & 2 \\
\hline 22 & PA-4 & PPD-4 & $8: 1$ & 1 & 0 \\
\hline 23 & PA-4 & PPD-5 & $4: 1$ & 1 & 1 \\
\hline 24 & PA-4 & PPD-6 & $1: 1$ & 2 & 1 \\
\hline 25 & PA-4 & PPD-7 & $1: 4$ & 1 & 2 \\
\hline
\end{tabular}

Table 4. Range analysis of orthogonal experiment.

\begin{tabular}{|c|c|c|c|c|c|c|c|}
\hline \multicolumn{4}{|c|}{$\Delta \mathrm{SP}\left({ }^{\circ} \mathrm{C}\right)$} & \multicolumn{4}{|c|}{$\triangle \mathrm{CFPP}\left({ }^{\circ} \mathrm{C}\right)$} \\
\hline & PMA (A) & EVA (B) & Mixed Ratio (C) & & PMA (A) & EVA (B) & Mixed Ratio (C) \\
\hline K1 & 6 & 7 & 9 & K1 & 5 & 6 & 4 \\
\hline K2 & 14 & 5 & 10 & K2 & 8 & 4 & 3 \\
\hline K3 & 8 & 5 & 9 & K3 & 3 & 5 & 4 \\
\hline K4 & 8 & 16 & 4 & K4 & 7 & 9 & 8 \\
\hline K5 & 8 & 11 & 12 & K5 & 6 & 5 & 10 \\
\hline $\mathrm{R} 1$ & 1.2 & 1.4 & 1.8 & $\mathrm{R} 1$ & 1 & 1.2 & 0.8 \\
\hline $\mathrm{R} 2$ & 2.8 & 1 & 2 & $\mathrm{R} 2$ & 1.6 & 0.8 & 0.6 \\
\hline $\mathrm{R} 3$ & 1.6 & 1 & 1.8 & $\mathrm{R} 3$ & 0.6 & 1 & 0.8 \\
\hline $\mathrm{R} 4$ & 1.6 & 3.2 & 0.8 & $\mathrm{R} 4$ & 1.4 & 1.8 & 1.6 \\
\hline R5 & 1.6 & 2.2 & 2.4 & $\mathrm{R} 5$ & 1.2 & 1 & 2 \\
\hline $\mathrm{R}$ & 1.6 & 2.2 & 1.6 & $\mathrm{R}$ & 1 & 1 & 1.4 \\
\hline Optimal level & A2 & B4 & C5 & Optimal level & A2 & B4 & C5 \\
\hline
\end{tabular}

According to the judgment of the range, the influence of this experimental factor on $\triangle \mathrm{SP}$ is $\mathrm{B}>\mathrm{A}=\mathrm{C}$; the influence of this experimental factor on $\triangle \mathrm{CFPP}$ is $\mathrm{C}>\mathrm{A}=\mathrm{B}$. It can be seen from the calculation results in the table that the best operating conditions are $\mathrm{A} 2 \mathrm{~B} 4 \mathrm{C} 5$. The best process conditions obtained are mixing PMA-2 and PPD- 6 with a mass ratio of 1:8. 


\subsection{Analysis on the Enhancing Mechanism of Mixed CFI on Biodiesel Flow Properties}

\subsubsection{DSC Analysis}

Differential scanning calorimetry (DSC) can quantitatively determine the effect of CFI on the energy change of biodiesel during the phase change process [30,31]. Therefore, the DSC test of blank biodiesel and biodiesel added with $0.1 \%$ mixed CFI (PMA-2 and PPD-6, a mixed mass ratio of 1:8, the same below), the DSC curve is shown in Figure 1 and the data analysis is listed in Table 5.

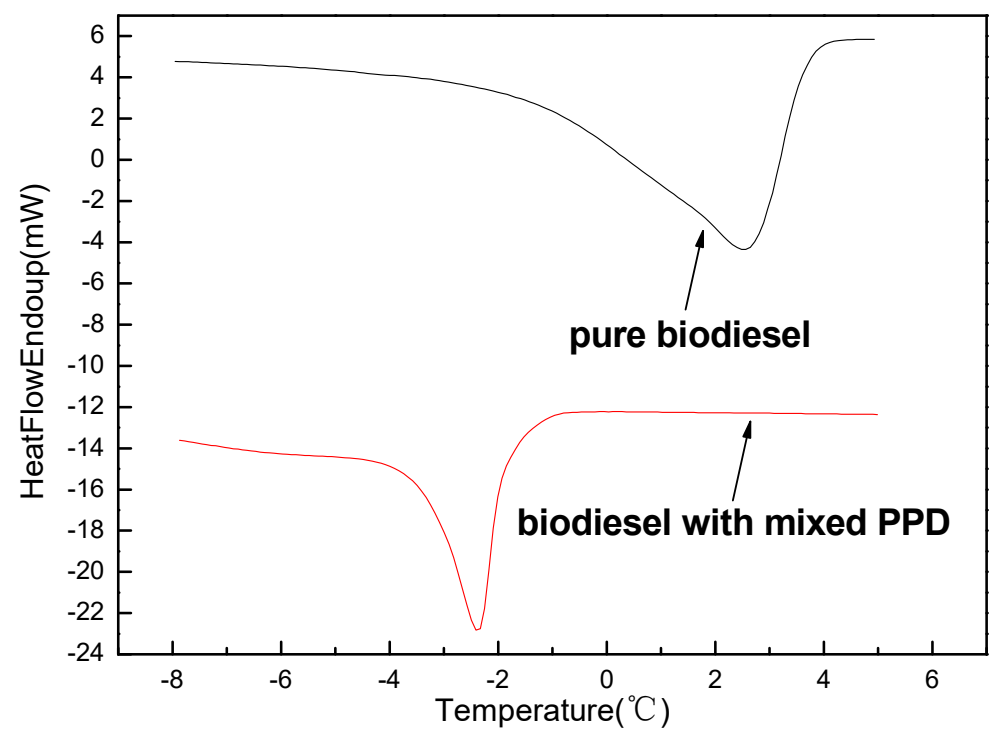

Figure 1. DSC curve of blank and biodiesel with mixed CFI.

Table 5. DSC analysis results.

\begin{tabular}{cccccc}
\hline Sample & Onset $/{ }^{\circ} \mathbf{C}$ & Peak $/{ }^{\circ} \mathbf{C}$ & Endset $/{ }^{\circ} \mathbf{C}$ & $\Delta \mathbf{H} / \mathbf{J} \cdot \mathbf{g}^{\mathbf{1}}$ & Area/mJ \\
\hline Pure biodiesel & 2.56 & 4.26 & -17.546 & -55.369 & 538.189 \\
Biodiesel with mixed CFI & -1.86 & -2.41 & -14.915 & -32.218 & 299.947 \\
\hline
\end{tabular}

It is recognized that the onset temperature of the crystallization peak in the diesel DSC curve with the heat flow rate as the ordinate and temperature as the abscissa reflected the temperature at which the diesel began to precipitate wax crystals. The slope of the crystallization peak reflected the rate of precipitation of wax crystals in diesel oil, and the solid-liquid phase transformation energy (the absolute value of $\Delta \mathrm{H}$ ) reflected the stability of the dispersion system where the wax crystals were located [35].

As can be seen in Table 5, after adding $0.1 \%$ mixed CFI to biodiesel, the crystal precipitation temperature (Onset) changed significantly to $-1.86^{\circ} \mathrm{C}$, and the peak crystallization temperature (Peak) decreased to $-2.41^{\circ} \mathrm{C}$. The slope of the peak did not change much, and the phase transition energy in the whole process was reduced from 55.369 to 32.218 . This showed that the mixed CFI reduced the temperature at which biodiesel started to precipitate crystals and had little effect on the slope of the biodiesel crystallization peak. The smaller the slope of the biodiesel crystallization peak, the slower the crystallization rate of diesel wax, which in turn indicated that the mixed CFI did not change the crystallization rate of the biodiesel wax; the absolute value of the solid-liquid phase transformation energy $(\Delta \mathrm{H})$ of the phase changed the process of the biodiesel became smaller after the addition of the $\mathrm{CFI}$, indicating that the low temperature depressant increased the stability of the wax crystal in the dispersed system. The crystallization peak area of biodiesel with mixed CFI was $299.947 \mathrm{~mJ}$, which was smaller than pure biodiesel, indicating that the number of precipitated crystals was also less. In summary, after adding a mixed CFI to biodiesel, the CFI mainly penetrated the nucleus of fatty acid 
methyl ester crystals through the polar groups in its molecular structure, and the non-polar groups were distributed in the crystals' surface to improve the stability of the dispersion system where the wax crystals are located to play a role in depressing solidifying point.

\subsubsection{XRD Analysis}

X-ray diffraction spectroscopy $(\mathrm{XRD})$ can analyze the lattice parameters of the wax crystals precipitated in biodiesel, to understand the structure of the wax crystals [32]. However, since biodiesel is a volatile liquid, and its research needs to be carried out in a low temperature environment, most of the previous researches is limited to offline analysis, that is, first reduce biodiesel with mixed CFI to the required temperature, and then perform XRD scanning. This can only make a rough analysis of the growth of diesel wax crystals at low temperatures, and it is impossible to continuously observe the crystal changes of wax crystals in diesel at different temperatures in time, especially for the wax at the cold filter plugging point where the low-temperature performance of biodiesel is extremely critical. The crystal change is not conducive to the in-depth study of its solidifying point reduction mechanism. Therefore, this article and the Institute of Organic Chemistry of the Chinese Academy of Sciences tried to use low-temperature in-situ XRD to analyze the CFI mechanism. Take the solidifying point of pure biodiesel at $6^{\circ} \mathrm{C}$ as the test temperature. The X-ray diffraction pattern of pure biodiesel and biodiesel with $0.1 \%$ mixed CFI at $6{ }^{\circ} \mathrm{C}$ is shown in Figure 2, and the XRD diffraction peak data analysis is shown in Tables 6 and 7.

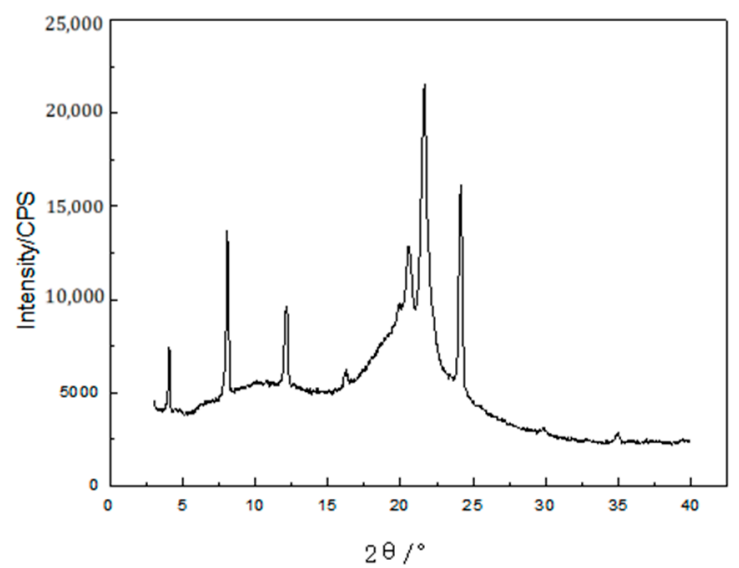

Pure biodiesel, $6{ }^{\circ} \mathrm{C}$

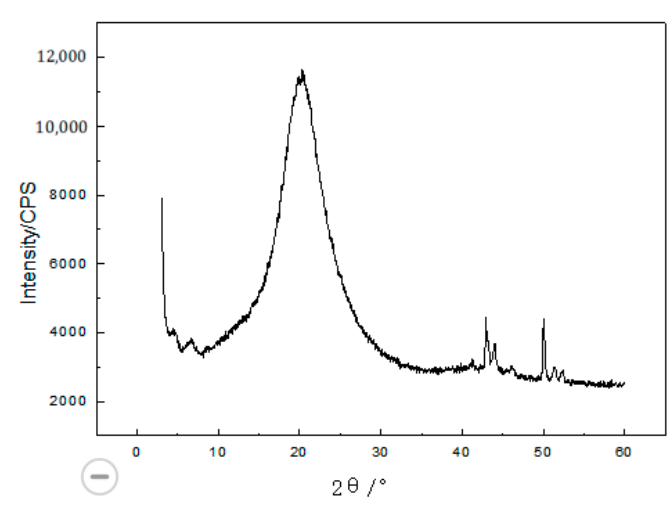

Biodiesel with mixed CFI, $6{ }^{\circ} \mathrm{C}$

Figure 2. XRD patterns of different biodiesel.

Table 6. Diffraction peak analysis results.

\begin{tabular}{ccccccc}
\hline \multirow{3}{*}{ Temperature $\left({ }^{\circ} \mathbf{C}\right)$} & \multicolumn{3}{c}{ Pure Biodiesel } & \multicolumn{3}{c}{ Add Mixed CFI Biodiesel } \\
\cline { 2 - 7 } & $\mathbf{2 \theta}$ & $\mathbf{d}(\mathbf{A})$ & Peak Area & $\mathbf{2 \theta}$ & $\mathbf{d}(\mathbf{\theta})$ & Peak Area \\
\hline & 4.073 & 21.678 & 15,735 & 4.639 & 19.033 & 7625 \\
& 8.083 & 10.929 & 57,856 & 6.737 & 13.109 & 13,513 \\
& 12.169 & 7.627 & 39,714 & 20.261 & 4.379 & 919 \\
6 & 16.255 & 5.448 & 7338 & 41.246 & 2.187 & 2857 \\
& 20.569 & 4.315 & 42,258 & 42.878 & 2.107 & 13,782 \\
& 21.628 & 4.106 & 178,891 & 43.985 & 2.057 & 8680 \\
& 24.125 & 3.686 & 86,422 & 46.084 & 1.968 & 2773 \\
& 29.838 & 2.992 & 2901 & 50.048 & 1.821 & 16,083 \\
& 34.946 & 2.565 & 5203 & 51.388 & 1.777 & 6039 \\
& 36.913 & 2.433 & 966 & 52.379 & 1.745 & 3447 \\
\hline
\end{tabular}


Table 7. XRD data analysis.

\begin{tabular}{cccc}
\hline \multicolumn{2}{c}{ Pure Biodiesel } & \multicolumn{2}{c}{ Add Mixed CFI Biodiesel } \\
\hline $\mathrm{S}$ & $\mathrm{A}$ & $\mathrm{S}$ & $\mathrm{A}$ \\
0.720 & 437,284 & 0.012 & 75,718 \\
\hline
\end{tabular}

It can be seen from Figure 2 that the $2 \theta$ of pure biodiesel and biodiesel with mixed CFI has a wide diffuse scattering peak between $10^{\circ}$ and $30^{\circ}$, and the $2 \theta$ of pure biodiesel is at $5.5^{\circ}, 21.63^{\circ}, 28.8^{\circ}$, $34.9^{\circ}$. There are sharp diffraction peaks near $36.9^{\circ}$, and the $2 \theta$ of the biodiesel with mixed CFI has sharp diffraction peaks near $5.6^{\circ}, 20.6^{\circ}, 42.6^{\circ}, 46.3^{\circ}$, and $51.3^{\circ}$, indicating that both of them precipitated amorphous and crystal wax. The two diffuse scattering peaks have the same peak shape width, which indicated that the amount of amorphous wax precipitated by the two is not much different. According to references [36,37], the wax crystal peaks of the XRD pattern are analyzed, and the results are shown in Table 3. It can be seen that the crystal peak area of pure biodiesel is much larger than that of biodiesel with mixed CFI, indicating that at the same temperature and the number of precipitated crystals in the biodiesel with mixed CFI is greatly reduced. The different $S$ values in pure biodiesel (0.720) and biodiesel with additive (0.012) indicates that the CFI changed the growth mode of wax crystals. The content of precipitated orthorhombic crystals is reduced, monoclinic crystals, and the content of orthorhombic crystals increases, while monoclinic crystals are not easy to aggregate and grow. The presence of orthorhombic crystals in the liquid phase is advantageous because it can delay the formation of three-dimensional network waxy structure, so crystals are smaller in size and easier to pass through the filter. In addition, the amount of wax crystals in the biodiesel with mixed CFI is also less, so the overall result was that the cold filter plugging point of the biodiesel with mixed CFI is lower.

\subsubsection{Polarized Light Microscope Analysis}

The low-temperature polarizing microscope can observe the changes of wax crystals in diesel before and after adding additives online $[38,39]$. The cold filter plugging point of the biodiesel with mixed CFI is $-1{ }^{\circ} \mathrm{C}$, so this experiment uses a polarizing microscope to study the crystal morphology of pure biodiesel and biodiesel diesel with $0.1 \%$ mixed CFI at $-1{ }^{\circ} \mathrm{C}$. The magnification is 200 times and the photos are shown in Figure 3.

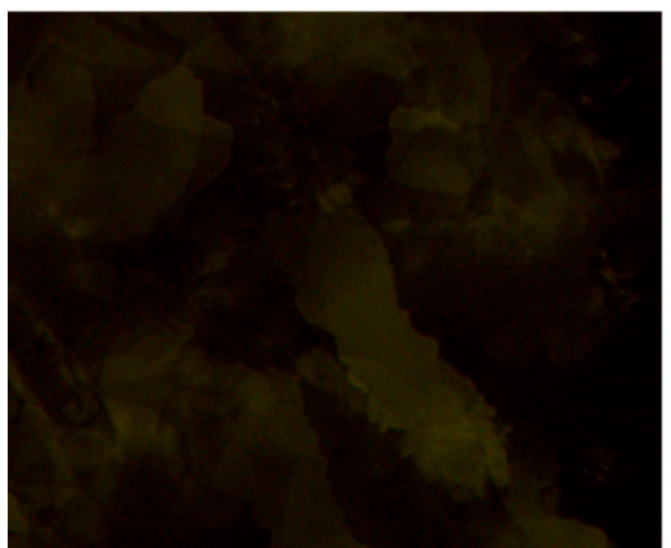

Pure biodiesel

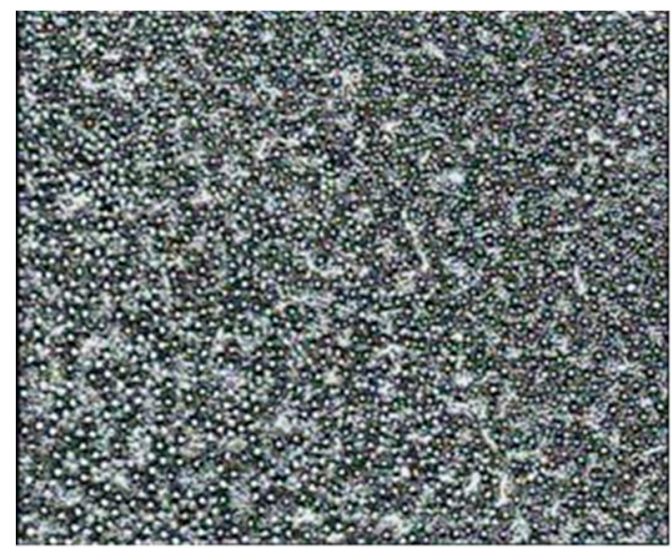

Biodiesel with mixed CFI

Figure 3. Low-temperature polarizing microscope photos of biodiesels with or without mixed CFI at $-1{ }^{\circ} \mathrm{C}$.

It can be seen from Figure 3 that at $-1{ }^{\circ} \mathrm{C}$, there are some long strips of crystals densely distributed in the pure biodiesel, and they are bonded together. After being treated with the mixed CFI, a large 
number of small spherical crystals are distributed inside the biodiesel system at $-1{ }^{\circ} \mathrm{C}$, but there is no tendency to stick, and the crystals are more dispersed than pure biodiesel. This showed that at low temperature, various fatty acid methyl esters in biodiesel gradually precipitate out and exist as long strips of crystals and adhere to each other. As the temperature decreases, the crystals increase and adhere to form a three-dimensional network structure, which envelops the organisms. The liquid component of diesel fuel, so that biodiesel lost its flow properties. After adding a mixed CFI to biodiesel, the CFI penetrates the nucleus of fatty acid methyl esters through the polar groups in its molecular structure to have a eutectic effect with it, and the non-polar groups are distributed in the crystal surface which changed the interface properties of the crystal, thereby changing the crystal shape and dispersion state, improving the low-temperature flow properties of biodiesel.

\section{Conclusions}

It shows that most of the commonly used cold flow improvers have a certain cold flow improver effect on biodiesel, but most of the cold flow improvers are not effective. Therefore, it is particularly important to develop new and efficient biodiesel cold flow improvers or well-designed mixed cold flow improvers. As long as the appropriate mixing ratio is adopted, the compounding use of cold flow improver has a better cold flow improving effect than the single ones on biodiesel. When the optimal mixing mass ratio of PMA-2 and PPD-6 is 8:1. DSC analysis shows that after adding a mixed CFI to biodiesel, the CFI mainly penetrates the nucleus of fatty acid methyl ester crystals through the polar groups in its molecular structure, and the non-polar groups are distributed in the crystals. Low-temperature XRD analysis showed that the CFI in the biodiesel with mixed CFI changed the growth mode of wax crystals, the content of precipitated orthorhombic crystals decreased, the content of monoclinic crystals and orthorhombic crystals increased, and the crystal size in the system was smaller and easy to pass through the filter. The polarized light microscope shows that the CFI penetrates the nucleus of fatty acid methyl ester through the polar group in its molecular structure to have a eutectic effect with it, thereby changing the crystal form and the dispersed state, thus improving the low temperature flow properties of biodiesel.

Author Contributions: Conceptualization, L.C.; data curation, L.C.; formal analysis, S.N.; investigation, S.N.; writing-original draft, S.N.; writing—review \& editing, L.C. All authors have read and agreed to the published version of the manuscript.

Funding: This research received no external funding.

Acknowledgments: We thank for the help from Sheng Han's group in carrying out part of the tests on the cold filter plugging points and the low temperature XRD of our samples.

Conflicts of Interest: The authors declare no conflict of interest.

\section{References}

1. Dwivedi, G.; Sharma, M.P. Investigation and improvement in cold flow properties of pongamia biodiesel. Waste Biomass Valori. 2015, 6, 73-79. [CrossRef]

2. Unlu, D.; Boz, N.; Ilgen, O.; Hilmioglu, N. Improvement of fuel properties of biodiesel with bioadditive ethyl levulinate. Open Chem. 2018, 16, 647-652. [CrossRef]

3. Xue, Y.; Yang, C.; Xu, G.W.; Zhao, Z.C.; Lian, X.; Sheng, H.; Lin, H.L. The influence of polymethyl acrylate as a pour point depressant for biodiesel. Energy Source Part A 2017, 39, 17-22. [CrossRef]

4. Lapuerta, M.; Gonzalez-Garcia, I.; Cespedes, I.; Estevez, C.; Bayarri, N. Improvement of cold flow properties of a new biofuel derived from glycerol. Fuel 2019, 242, 794-803. [CrossRef]

5. Cao, L.C.; Zhang, S.C. Production and characterization of biodiesel derived from Hodgsonia macrocarpa seed oil. Appl. Energy 2015, 146, 135-140. [CrossRef]

6. Curran, M.A. Assessing environmental impacts of biofuels using lifecycle-based approaches. Manag. Environ. Qual. 2012, 24, 34-52. [CrossRef]

7. Milazzo, M.F.; Spina, F. The use of the risk assessment in the life cycle assessment framework Human health impacts of a soy-biodiesel production. Manag. Environ. Qual. 2015, 26, 389-406. [CrossRef] 
8. Nemanashi, M.; Noh, J.H.; Meijboom, R. Hydrogenation of biomass-derived levulinic acid to gamma-valerolactone catalyzed by mesoporous supported dendrimer-derived $\mathrm{Ru}$ and $\mathrm{Pt}$ catalysts: An alternative method for the production of renewable biofuels. Appl. Catal. A Gen. 2018, 550, 77-89. [CrossRef]

9. Milazzo, M.F.; Spina, F.; Cavallaro, S.; Bart, J.C.J. Sustainable soy biodiesel. Renew. Sustain. Energy Rev. 2013, 27, 806-852. [CrossRef]

10. Mohanan, A.; Bouzidi, L.; Li, S.J.; Narine, S.S. Mitigating crystallization of saturated fames in biodiesel: 1. Lowering crystallization temperatures via addition of metathesized soybean oil. Energy 2016, 96, 335-345. [CrossRef]

11. Wang, J.N.; Zhao, W.N.; Ai, Y.N.; Chen, H.Y.; Cao, L.C.; Han, S. Improving the fuel properties of biodiesel via complementary blending with diesel from direct coal liquefaction. RSC Adv. 2015, 5, 45575-45581. [CrossRef]

12. Kim, D.S.; Hanifzadeh, M.; Kumar, A. Trend of Biodiesel Feedstock and Its Impact on Biodiesel Emission Characteristics. Environ. Prog. Sustain. Energy 2018, 37, 7-19. [CrossRef]

13. Zhou, M.A.; He, Y.; Chen, Y.W.; Yang, Y.P.; Lin, H.L.; Han, S. Synthesis and Evaluation of Terpolymers Consist of Methacrylates with Maleic Anhydride and Methacrylic Morpholine and Their Amine Compound as Pour Point Depressants in Diesel Fuels. Energy Fuel 2015, 29, 5618-5624. [CrossRef]

14. Abe, M.; Hirata, S.; Komatsu, H.; Yamagiwa, K.; Tajima, H. Thermodynamic selection of effective additives to improve the cloud point of biodiesel fuels. Fuel 2016, 171, 94-100. [CrossRef]

15. Hosseinzadeh-Bandbafha, H.; Tabatabaei, M.; Aghbashlo, M.; Khanali, M.; Demirbas, A. A comprehensive review on the environmental impacts of diesel/biodiesel additives. Energy Convers. Manag. 2018, 174, 579-614. [CrossRef]

16. Maglinao, R.L.; Resurrection, E.P.; Kumar, S.; Maglinao, A.L.; Capareda, S.; Moser, B.R. Hydrodeoxygenation-Alkylation Pathway for the Synthesis of a Sustainable Lubricant Improver from Plant Oils and Lignin-Derived Phenols. Ind. Eng. Chem. Res. 2019, 58, 4317-4330. [CrossRef]

17. Srikanth, H.V.; Venkatesh, J.; Godiganur, S.; Venkateswaran, S.; Manne, B. Bio-based diluents improve cold flow properties of dairy washed milk-scum biodiesel. Renew. Energy 2017, 111, 168-174. [CrossRef]

18. Li, H.; Wang, J.G.; Shen, B.X. The rheological properties of biodiesel derived from cottonseed oil. Energy Source Part A 2016, 38, 3181-3186. [CrossRef]

19. Lian, X.; Xue, Y.; Xu, G.W.; Zhao, Z.C.; Sheng, H.; Lin, H.L. Effect of methyl acetoacetate as a potential cold flow improver for biodiesel. Energy Source Part A 2017, 39, 97-102. [CrossRef]

20. Evcil, A.; Al-Shanableh, F.; Savas, M.A. Variation of solid fraction with cold flow properties of biodiesel produced from waste frying oil. Fuel 2018, 215, 522-527. [CrossRef]

21. Zhou, M.A.; He, Y.; Lin, H.L.; Han, S. Effect of MC-MA polymer pour point depressants on the flow properties of biodiesel. Energy Source Part A 2016, 38, 1962-1968. [CrossRef]

22. Srikanth, H.V.; Venkatesh, J.; Godiganur, S.; Manne, B. Acetone and Diethyl ether: Improve cold flow properties of Dairy Washed Milkscum biodiesel. Renew. Energy 2019, 130, 446-451. [CrossRef]

23. Liu, H.; Jiang, S.S.; Guo, H.S.; Han, S.; Yang, C.; Jiang, J.Z. A new kind of pour point depressant: Diesel from direct coal liquefaction. Fuel Process. Technol. 2016, 149, 285-289. [CrossRef]

24. Zhao, Z.C.; Xue, Y.; Xu, G.W.; Zhou, J.W.; Lian, X.; Liu, P.; Chen, D.M.; Han, S.; Lin, H.L. Effect of the nano-hybrid pour point depressants on the cold flow properties of diesel fuel. Fuel 2017, 193, 65-71. [CrossRef]

25. Imdadul, H.K.; Masjuki, H.H.; Kalam, M.A.; Zulkifli, N.W.M.; Rashed, M.M.; Rashedul, H.K.; Monirul, I.M.; Mosarof, M.H. A comprehensive review on the assessment of fuel additive effects on combustion behavior in CI engine fuelled with diesel biodiesel blends. RSC Adv. 2015, 5, 67541-67567. [CrossRef]

26. Abe, M.; Komatsu, H.; Yamagiwa, K.; Tajima, H. Effect of nonionic surfactants on the low temperature winterization separation of fatty acid methyl ester mixtures. Fuel 2017, 190, 351-358. [CrossRef]

27. Roy, M.M.; Calder, J.; Wang, W.; Mangad, A.; Diniz, F.C.M. Emission analysis of a modern Tier 4 DI diesel engine fueled by biodiesel-diesel blends with a cold flow improver (Wintron Synergy) at multiple idling conditions. Appl. Energy 2016, 179, 45-54. [CrossRef]

28. Eiadtrong, S.; Maliwan, K.; Prateepchaikul, G.; Kattiyawan, T.; Thephsorn, P.; Leevijit, T. Preparation, important fuel properties, and comparative use of un-preheated palm fatty acid distillate-diesel blends in a single cylinder diesel engine. Renew. Energy 2019, 134, 1089-1098. [CrossRef] 
29. Zhao, W.N.; Xue, Y.; Ma, P.; Ma, W.F.; Wang, J.N.; Lu, D.L.; Han, S. Improving the cold flow properties of high-proportional waste cooking oil biodiesel blends with mixed cold flow improvers. RSC Adv. 2016, 6, 13365-13370. [CrossRef]

30. Cao, L.C.; Wang, J.N.; Liu, K.J.; Han, S. Ethyl acetoacetate: A potential bio-based diluent for improving the cold flow properties of biodiesel from waste cooking oil. Appl. Energy 2014, 114, 18-21. [CrossRef]

31. Tasic, I.; Tomic, M.D.; Aleksic, A.L.; Durisic-Mladenovic, N.; Martinovic, F.L.; Micic, R.D. Improvement of low-temperature characteristics of biodiesel by additivation. Hem. Ind. 2019, 73, 103-114. [CrossRef]

32. Wang, W.C.; Li, F.S.; Li, Y. Effect of biodiesel ester structure optimization on low temperature performance and oxidation stability. J. Mater. Res. Technol. 2020, 9, 2727-2736. [CrossRef]

33. Rajaeifar, M.A.; Abdi, R.; Tabatabaei, M. Expanded polystyrene waste application for improving biodiesel environmental performance parameters from life cycle assessment point of view. Renew. Sustain. Energy Rev. 2017, 74, 278-298. [CrossRef]

34. Verma, P.; Sharma, M.P.; Dwivedi, G. Evaluation and enhancement of cold flow properties of palm oil and its biodiesel. Energy Rep. 2016, 2, 8-13. [CrossRef]

35. Dunn, R.O.; Ngo, H.L.; Haas, M.J. Branched-Chain Fatty Acid Methyl Esters as Cold Flow Improvers for Biodiesel. J. Am. Oil Chem. Soc. 2015, 92, 853-869. [CrossRef]

36. Cao, L.C.; Wang, J.N.; Liu, C.; Chen, Y.W.; Liu, K.J.; Han, S. Ethylene vinyl acetate copolymer: A bio-based cold flow improver for waste cooking oil derived biodiesel blends. Appl. Energy 2014, 132, 163-167. [CrossRef]

37. Madihalli, C.; Sudhakar, H.; Doble, M. Mannosylerythritol Lipid-A as a Pour Point Depressant for Enhancing the Low-Temperature Fluidity of Biodiesel and Hydrocarbon Fuels. Energy Fuel 2016, 30, 4118-4125. [CrossRef]

38. Wang, J.N.; Cao, L.C.; Han, S. Effect of polymeric cold flow improvers on flow properties of biodiesel from waste cooking oil. Fuel 2014, 117, 876-881. [CrossRef]

39. Mohanan, A.; Bouzidi, L.; Narine, S.S. Harnessing the synergies between lipid-based crystallization modifiers and a polymer pour point depressant to improve pour point of biodiesel. Energy 2017, 120, 895-906. [CrossRef]

(C) 2020 by the authors. Licensee MDPI, Basel, Switzerland. This article is an open access article distributed under the terms and conditions of the Creative Commons Attribution (CC BY) license (http://creativecommons.org/licenses/by/4.0/). 